\title{
Comunidade Criativa: um estudo de caso sobre a Horta Comunitária do Parque do Martelo
}

\author{
Creative Community: A case study of the Parque do Martelo's Community Garden.
}

PERNES, Fernanda Gusmão; Mestranda; PPG Design/PUC-Rio, fernandagusmaopernes@gmail.com

CIPOLLA, Carla; Doutora em Design pelo Politécnico de Milão, Professora na Coppe/UFRJ, carla.cipolla@gmail.com

\section{Resumo}

Este artigo visa analisar uma iniciativa urbana em uma abordagem do Design para Inovação Social e Sustentabilidade, com o objetivo de compreender suas relações interpessoais e institucionais. 0 foco do estudo é a horta comunitária do Parque do Martelo (Humaitá), no Rio de Janeiro. A metodologia inclui revisão da literatura e pesquisa qualitativa por meio de observação participante e entrevistas contextuais, sendo os resultados organizados em um Mapa Mental e em um Mapa de Stakeholders. Tais resultados apontam que a horta contribui para a promoção da sustentabilidade no contexto urbano por meio de um sistema de valores e da articulação mutuamente benéfica de uma rede de atores locais. 0 estudo de caso evidenciou a importância das interações de caráter interpessoal para o sustento da iniciativa.

Palavras-chave: Design; Inovação Social; Comunidades Criativas.

\begin{abstract}
This paper aims to analyze an urban initiative from the perspective of Design for Social Innovation and Sustainability, with the objective of understanding its interpersonal and institutional relations. The focus of the study is the community garden located at Parque do Martelo (Humaitá), in the city of Rio de Janeiro. The methodology includes a literature review, and a qualitative research study, conducted through participant observation and semi-structured interviews; the results were organized in the form of a Mental Map and a Map of Stakeholders. The results indicate that the community garden may contribute to the promotion of sustainability in the urban context, by means of a system of values and the mutually beneficial articulation of a network of local actors. The importance of interpersonal interactions to sustain the initiative was evidenced.
\end{abstract}

Keywords: Design; Social Innovation; Creative Communities. 


\section{Introdução}

O cenário atual do Rio de Janeiro apresenta mobilizações de pessoas em prol de ações sustentáveis, tais como o crescimento contínuo das hortas comunitárias. Essas hortas demonstram engajamento e esforço de pessoas em busca da melhora da qualidade de vida junto ao meio ambiente, ao bairro e à cidade. Espaços que antes estavam em desuso e abandono, hoje estão dando lugar ao plantio. As hortas comunitárias permitem um encontro com a vizinhança e a construção de um novo lugar.

Grupos de pessoas vêm resgatando o contato com a natureza e o convívio com a vizinhança por meio das hortas comunitárias. Estes grupos são denominados comunidades criativas, que de acordo com Meroni são "pessoas que, de forma colaborativa, inventam, aprimoram e gerenciam soluções inovadoras para novos modos de vida" (MERONI, 2007, apud MANZINI, 2008, p. 64). Este artigo traz a abordagem do grupo DESIS (Design for Social Innovation and Sustainability), que trata as comunidades criativas como um caso de design e inovação social.

O termo inovação social significa "mudanças no modo como indivíduos ou comunidades agem para resolver seus problemas ou criar novas oportunidades" (MANZINI, 2008, p.61). Neste artigo será analisado o caso da horta comunitária do Parque do Martelo por meio de um estudo de caso. O objetivo será compreender como as relações construídas na horta comunitária do Parque do Martelo se sustentam.

O Parque do Martelo é um local propício para a presente análise devido ao seu foco na prática do convívio e da sustentabilidade desde o seu surgimento, em 2005. Apoiado pela Associação dos Moradores do Alto Humaitá (AMAH) e por seus amigos, o parque oferece uma horta comunitária, onde voluntários se reúnem para cuidar da irrigação e realizar mutirões de plantio. A escolha do parque se fez devido ao grande interesse da pesquisadora pelo tema das hortas comunitárias e pela sua participação como voluntária e frequentadora do local.

A história do parque começa nos anos 80 , com a luta dos moradores frente à construção de um grande condomínio na rua Miguel Pereira. A união dessas pessoas permitiu um espaço de luta e conquista, junto a muitas iniciativas sociais. Uma das maiores iniciativas foi a realização de uma festa junina, que engajou a maioria dos moradores numa festa bonita e organizada. Encantados com o resultado da festa, os residentes perceberam o quanto eram fortes e unidos, então começaram a organizar mais encontros, como reuniões para tratar assuntos da rua e sarais musicais. Visto que a construção do condomínio era um dos assuntos de maior importância e com o apoio da Associação de Moradores de Botafogo, os residentes resolveram criar a AMAH (Associação dos Moradores do Alto Humaitá) com o objetivo de unir forças contra a construção do condomínio de 250 apartamentos na rua Miguel Pereira.

Após 20 anos de luta, o terreno foi cedido pela Prefeitura do Rio de Janeiro para a AMAH por meio de uma concessão para uso e limpeza do capim colonial, considerado uma praga na Mata Atlântica. Desde então, a AMAH soma esforços para a manutenção do terreno e trabalha na criação de ações e projetos voltados para o meio ambiente e sustentabilidade.

De acordo com a descrição de uma moradora, no ano de 2005 os próprios moradores começaram a limpeza do local e levam doações de brinquedos para que as crianças tivessem um espaço junto à natureza para brincar. Era o início da formação do parque, que mais tarde resgatou relações de boa vizinhança, confiança, afetos e um grande senso de comunidade. Essa relação de 
confiança cresceu e a área do parque de hoje conta com uma horta comunitária, onde são realizados mutirões mensais para plantio, cuidados, rega e troca de sementes. É dentro dos mutirões de plantio que acontecem as principais interações nas hortas. Moradores da vizinhança e também frequentadores de outros bairros vêm trabalhar voluntariamente na horta, plantando sementes, arrumando os canteiros, regando a terra, saudando o sol e o alimento que sempre é oferecido nesta atividade de troca.

Existe uma importante relação entre a Prefeitura do Rio de Janeiro e os diretores do parque, pois somente com a concessão de uso que se faz permitida a utilização da área. Como o parque fica localizado em uma rua sem saída, outra relação importante é a da AMAH com a vizinhança que não frequenta o parque. A AMAH reúne esforços para valorizar a área e as ações do parque, porém nem toda vizinhança participa como contribuinte, voluntária e até mesmo a frequenta. As pessoas envolvidas no parque cultivam relações saudáveis entre si, desde os dois funcionários que vigiam o parque até os voluntários, frequentadores, parceiros e amigos. Uma relação bem forte é a da direção com a parceria do Ciclo Orgânico, uma pequena empresa que realiza a compostagem de resíduos orgânicos no parque e, em troca, oferece adubo para a horta.

\section{Quadro Conceitual}

\subsection{Hortas comunitárias}

A história das hortas comunitárias tem um forte papel na civilização quanto à formação das primeiras cidades. Para se estabelecer em um determinado território era necessário que o homem cultivasse o plantio e o seu próprio alimento. De uma era antiga para os dias de hoje, as hortas comunitárias estão presentes em diversas cidades do mundo. Nos anos 70, em Nova lorque, um movimento chamado Green Guerrillas (guerrilheiros verdes), liderado pela artista Liz Christy era formado por ativistas, que transformaram áreas degradadas em hortas comunitárias, mudando a percepção do local (PENIN, 2012). O projeto teve reconhecimento da prefeitura como ferramenta de recuperação da cidade baseado em estreitar laços de vizinhança e fornecer alimentos frescos.

Dentro da Zona Sul da cidade do Rio de Janeiro existem poucos locais destinados ao plantio. As hortas comunitárias no Rio vêm sendo a solução para estas pessoas que ocupam canteiros e espaços urbanos em desuso. Atualmente existem poucas hortas na cidade, porém, casos emergem progressivamente em que os participantes adotam canteiros ou ocupam territórios para desenvolver a construção da plantação, como a Horta da General (Laranjeiras), a Horta da Fonte da Saudade do coletivo Horta Nossa e a Horta dos Arcos da Lapa do grupo Plante Rio.

As iniciativas de hortas comunitárias possuem características próprias aos movimentos de busca da melhoria da qualidade de vida das pessoas no sentido de prover acessos a novos mercados. É possível fazer uma ligação das hortas comunitárias com o movimento do Slow Food (criado em 1989 por Carlo Petrini), por exemplo, que propagou a ideia de uma alimentação de melhor qualidade por meio de produtores locais, incentivando a pequena produção caseira de temperos e hortaliças (MANZINI, 2017). As hortas comunitárias trazem de volta a época de um tempo mais contemplativo e a valorização de produção local de alimentos.

$\mathrm{Na}$ cidade do Rio de Janeiro o movimento das hortas comunitárias acontece com maior força a partir do século XXI. Aparentemente este movimento parece pouco expressivo, mas vem engajando pessoas e voluntários. $\mathrm{O}$ trabalho nas hortas comunitárias é realizado por voluntários e 
conta com o apoio e motivação dessas pessoas. Dentro do tema, é importante perceber que as hortas comunitárias estão inseridas numa cultura local. Tanto nas cidades da Europa como nos Estados Unidos existe uma valorização dos jardins e áreas verdes, locais onde os cidadãos estão acostumados a estar nas horas de lazer. Entretanto, a cidade do Rio de Janeiro recentemente vem ganhando uma expressividade na atuação em hortas e jardins comunitários.

\subsection{Design para a sustentabilidade e o voluntariado criativo}

A presença das hortas comunitárias levanta a questão da criação de novos cenários e de como serão as cidades no futuro. Lugares como esse são importantes não só para o bem-estar das comunidades e indivíduos; eles se constroem como uma precondição para um sistema maior, um sistema natural, social e de produção mais resiliente. Um sistema capaz de se adaptar a acontecimentos inesperados e de sobreviver ao tempo (MANZINI, 2017).

Victor Papanek (2005), um dos primeiros designers a abordar a questão da sustentabilidade no design, ressalta a importância da ação voluntária e social na busca por resolver problemas ou criar novas oportunidades. As pessoas envolvidas em atividades voluntárias associadas à sustentabilidade das cidades são pessoas "não especialistas e com a capacidade natural para o design" (MANZINI, 2017, p. 51), a que o autor chama de designers difusos. De fato, a criatividade não está restrita aos designers, e não necessariamente um designer desenvolve soluções inovadoras e criativas. A criatividade é a "capacidade de imaginar algo que ainda não existe" e é algo que pode ser acessado por todos (MANZINI, 2017, p. 45). No entanto, Thackara (2008) questiona o mito da criatividade como alvo dos designers, já que estes poderiam buscar no passado soluções testadas e comprovadas que outras pessoas já criaram.

\subsection{Práticas comunitárias no contexto urbano}

Segundo Buber, as comunidades são como uma condição social primitiva e que, uma união entre pessoas "é o resultado de um processo natural e não algo imposto; é algo baseado em sua origem comum, costumes, propriedades etc." (BUBER, 1987, p. 83). Esses novos modos de vida sustentados pelas comunidades criativas geram uma ideia de bem-estar e uma construção social que se forma ao longo do tempo (MANZINI, 2008). É possível relacionar o bem-estar na sociedade do consumo à compra de produtos e serviços, o que vem ocasionando inúmeros danos ao planeta. Em contrapartida, surge uma nova consciência sustentável para as antigas formas de consumo e produção. Manzini (2008) fala de um bem estar relacionado ao uso, em que a posse dos produtos é deslocada para o acesso e consequentemente resultará numa experiência. A ideia de bem-estar vem redescobrindo a qualidade de vida de seu contexto, bem como o valor dos bens comuns e do tempo lento e contemplativo (MANZINI, 2008).

Na busca por uma qualidade de vida, uma solução seria viver em comunidade como um resgate da época em que faziam-se as coisas juntos, cuja cooperação era a base para se viver (SENNETT, 2012). Sennett (2012) define a cooperação como uma troca que acontece a partir de um encontro e que a ela está contida nas células humanas. A busca por esse encontro se concretiza na democratização social dos espaços territoriais que passam a ser lugares de práticas sustentáveis e conhecimento informal, a partir do envolvimento e participação. Com este espírito de comunidade, as pessoas passam a ter uma maior pertencimento ao território e engajamento.

Dessa forma, o objetivo amplo deste artigo é compreender como as relações construídas na horta comunitária do Parque do Martelo se sustentam. Para tanto, buscou-se trabalhar com a 
observação participante e entrevistas com mulheres de relevância para a construção e consolidação das práticas da comunidade criativa do parque. Como objetivo específico, este trabalho intenciona construir um sistema de registro dessa inovação social por meio de um Mapa Mental e de um Mapa de Stakeholders, representações gráficas cujas características conceituais e de elaboração são detalhadas a seguir.

Figura 1 - Horta comunitária do Parque do Martelo.

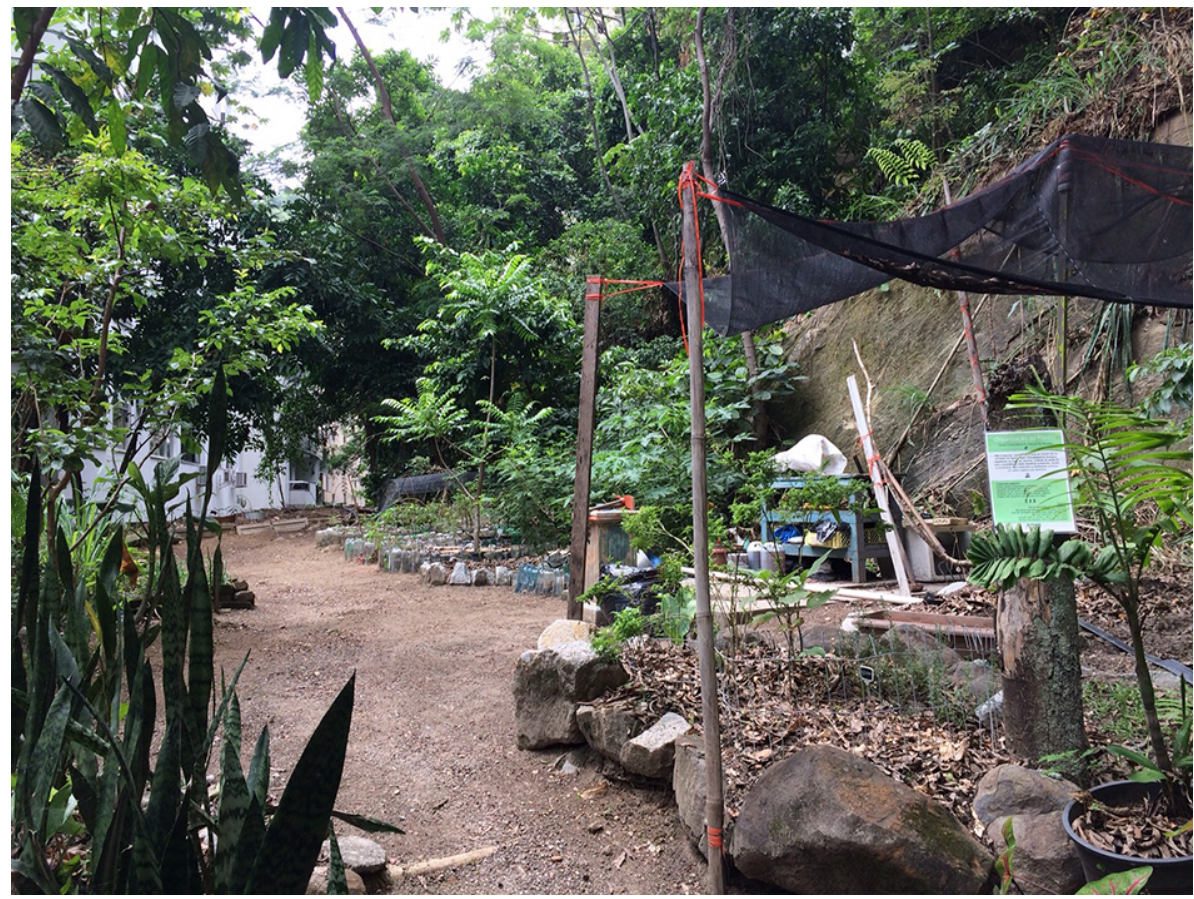

Fonte: o autor (2018).

\section{Metodologia}

A partir da revisão de literatura foi definida uma abordagem de pesquisa qualitativa, utilizando a metodologia do estudo de caso único para compreender mais profundamente as relações sociais estabelecidas na horta comunitária do Parque do Martelo (Humaitá, Rio de Janeiro). Houve uma vivência anterior a esta pesquisa, tendo esta o caráter de observação participante ao longo de tempo, realizada também de modo específico para o presente estudo. A coleta de dados foi feita a partir de duas entrevistas contextuais realizadas com atores relevantes para compreender alguns sistemas e relações no parque.

As falas das entrevistas e de palavras repetidas nos momentos comunitários, ouvidas durante o período de observação participante, formaram o método de coleta para elaboração do Mapa Mental, que é definido como se segue:

Os mapas mentais consistem em uma representação gráfica de um processo de aprendizagem integral (pois a sua elaboração estimula os dois hemisférios do cérebro ao mesmo tempo) que possibilita ao indivíduo maior capacidade de compreensão, aprendizagem e memorização (ESTUDO ESQUEMATIZADO, 2018, não p.).

O Mapa de Skateholders foi construído a partir das referências institucionais e comunitárias tecidas acerca do Parque do Martelo, bem como sobre sua horta. Um mapa de 
stakeholders é "uma representação visual ou física dos diversos grupos/públicos envolvidos em determinado serviço" (STICKDORN, 2014, p. 152). A partir da representação visual dos grupos de pessoas envolvidos na horta do Parque do Martelo é possível mapear as ações e relações de todos os envolvidos. Destaca-se que a construção desse diagrama se dá a partir das redes de relações enunciadas formal e informalmente na comunidade criativa do Parque do Martelo. A partir da observação participante e também tendo como base o discurso das entrevistadas, foi construído o mapa com os principais grupos envolvidos diretamente no parque.

\subsection{Entrevistas contextuais}

A escolha do uso das entrevistas contextuais para este estudo foi realizada porque esta técnica "permite que os entrevistadores observem e investiguem o comportamento" (STICKDORN, 2014, p. 164 dos entrevistados, que são conduzidos no ambiente e trazem a compreensão do contexto, além de situarem-se na relevância da construção da Associação e da horta. Para ter uma escuta mais ampla sobre a horta comunitária, uma das fundadoras do parque foi escolhida para contar sobre a história e os detalhes do ambiente. Foi selecionada também a atual arquiteta e paisagista da horta comunitária que está presente em todos os mutirões de plantio e que também realizou um projeto paisagista para a horta. As perguntas realizadas foram:

1 - Conte um pouco da história da horta comunitária do parque.

2 - Quais as atuas motivações da horta comunitária?

3 - Quais as principais barreiras encontradas na horta comunitária?

ATOR 1

O primeiro ator entrevistado acompanhou a formação do Parque do Martelo e fala sobre a área onde a horta comunitária se encontra, ao lado de uma encosta. Ele diz que a horta sofre com as chuvas fortes porque desce muita lama da encosta e destrói boa parte da plantação. Fala também que a AMAH e os amigos do parque sustentam o local com uma quantia trimensal de R\$ 150,00 , que é destinada às contas do parque e ao pagamento de dois funcionários. $O$ ator ainda relata que o maior desafio de hoje é de que a vizinhança se engaje nesta contribuição para que o parque amplie os seus recursos, e afirma que os contribuintes têm a consciência de que o parque valoriza seus imóveis e traz um bem-estar e uma boa convivência para a vizinhança. Conta que a atual área da horta comunitária estava cheia de entulhos de construções antigas que existiam no local e que contaram com o projeto de arquitetos e paisagistas para a regeneração do espaço com a fixação dos canteiros e das mudas. O entrevistado dá enfoque na força do movimento de equipe e diz que suas principais motivações pessoais são a qualidade de vida, o amor, a busca por uma vida e um mundo melhor, os bons relacionamentos e o auxílio na resolução de problemas.

\section{ATOR 2}

O ator 2 é responsável pelo projeto da horta do Parque do Martelo e atua como voluntário e líder dos mutirões mensais. Contou que tentou realizar um projeto de horta comunitária no Parque Guinle mas que não obteve sucesso, pois não teve apoio local. Diferente dessa situação, conta que no parque do martelo teve a possibilidade de realizar a horta. Em parceria com outra arquiteta, o entrevistado desenhou o atual projeto da horta comunitária. Menciona realizar seu trabalho com muito amor e está sempre disposto a ter novos encontros a cada mutirão. Deu início aos mutirões mensais que possibilita trocas de sementes e ampliou o desenho da horta. Atualmente a horta ganhou dois novos projetos: um berçário para mudas, um minhocário e uma 
composteira. Nesse novo desenho, a horta ganhou também um sistema de irrigação feito a partir de uma mangueira com furos, que irriga quase toda a área. Diz que uma de suas principais motivações é trazer uma consciência para a natureza e acredita que este movimento seja uma fonte de vida. Menciona gostar muito de plantar e colher os alimentos, colocar as mãos na terra e encontrar pessoas no espaço público.

\subsection{Observação Participante}

A observação participante se deu no período de março a dezembro de 2017, durante a realização dos mutirões de plantio no parque e de outras ações, com a presença de 15 pessoas em média, envolvidas nas atividades de plantio, colheita e irrigação da horta. O mutirão acontece mensalmente, geralmente no segundo domingo do mês, e é coordenado pelo ATOR 2 que sempre traz um suporte com várias mudas. A presença de um paisagista de origem estrangeira na horta é algo motivador, pois ele sempre está disposto a ajudar, possui muito conhecimento sobre as plantas e traz minhocas que aceleram o processo da compostagem. Observa-se que a horta comunitária é um espaço de encontro, onde as relações são o grande atrativo, visto que a produção de alimentos orgânicos fica em segundo plano. Dentro do mutirão é possível ver a colaboração em ação no plantio de mudas, troca de informações, irrigação e bem-estar também na pausa para beber uma água ou tomar um cafezinho.

\section{Resultados}

\subsection{Mapa Mental}

A escolha do mapa mental objetivou registrar e entender o que estava sendo produzido a partir dos termos identificados como organizadores do discurso da comunidade criativa do Parque do Martelo. O mapa, que enumera os valores envolvidos dentro das atividades da horta comunitária, apresenta as principais características envolvidas no mutirão de plantio da horta comunitária do Parque do Martelo a partir do discurso dos entrevistados.

$\mathrm{Na}$ construção do Mapa Mental foi diagnosticado, por meio de observação e das entrevistas, uma produção de valores tangíveis e intangíveis, como mostra a Figura 2. 
Figura 2 - Mapa mental da Horta comunitária

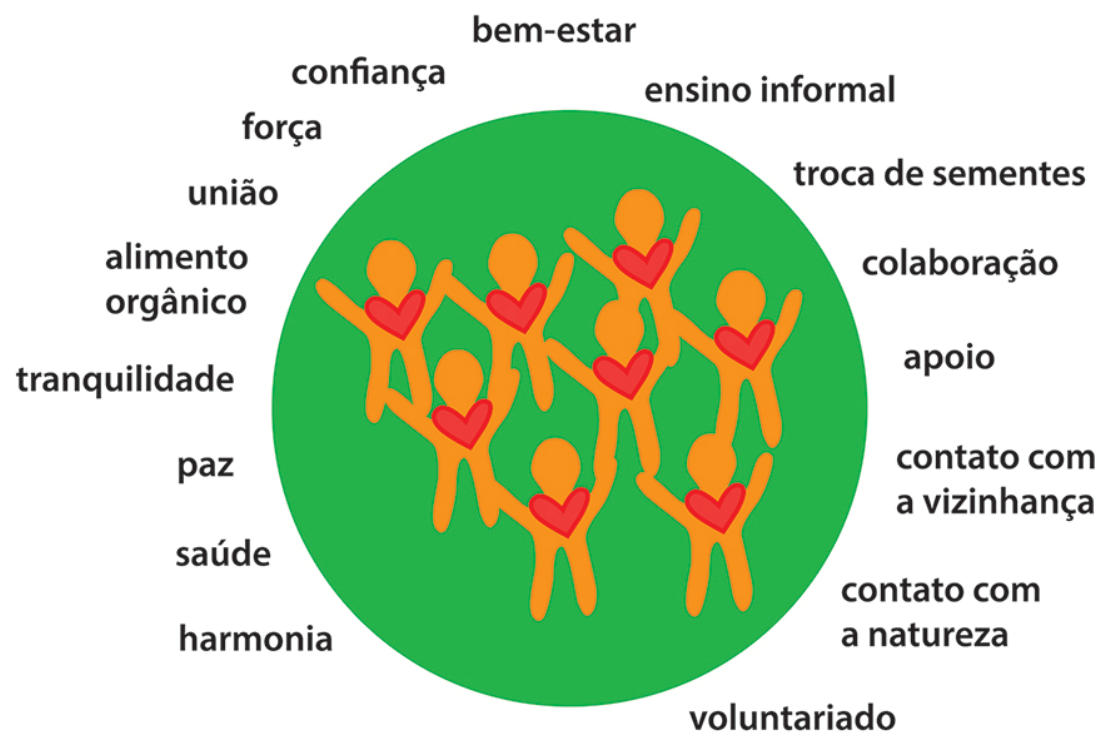

Fonte: o autor (2018).

\subsection{Mapa de Stakeholders}

Elaborado a partir de uma observação participante, o mapa se divide em grupos de stakeholders, ou seja, pessoas envolvidas na horta internamente e externamente.

A área do parque é de propriedade da Prefeitura do Rio de Janeiro e foi importante perceber que existe uma relação de confiança entre a prefeitura e a diretoria do parque. Sem a concessão da prefeitura, o Parque do Martelo não poderia existir. Em seguida, uma das principais relações é entre a diretoria e os amigos do parque, que funciona muito bem. Os amigos do parque são figuras importantes, pois são seus mantenedores, os quais contribuem com uma quantia mensal destinada a pagar as contas do parque (água, luz, materiais e funcionários). É possível destacar que metade dos moradores da rua são amigos do parque, e que sem eles o local não poderia existir. É importante ressaltar também a importância de se manter um relacionamento positivo com os demais moradores da rua - aqueles que não são os "amigos do parque" - uma vez que esta atitude está diretamente ligada às regras de convivência, tais como respeitar o trânsito da rua, a emissão sonora e todos os movimentos produzidos no parque para que haja uma relação de boa vizinhança. 
Figura 3 - Mapa de stakeholders.

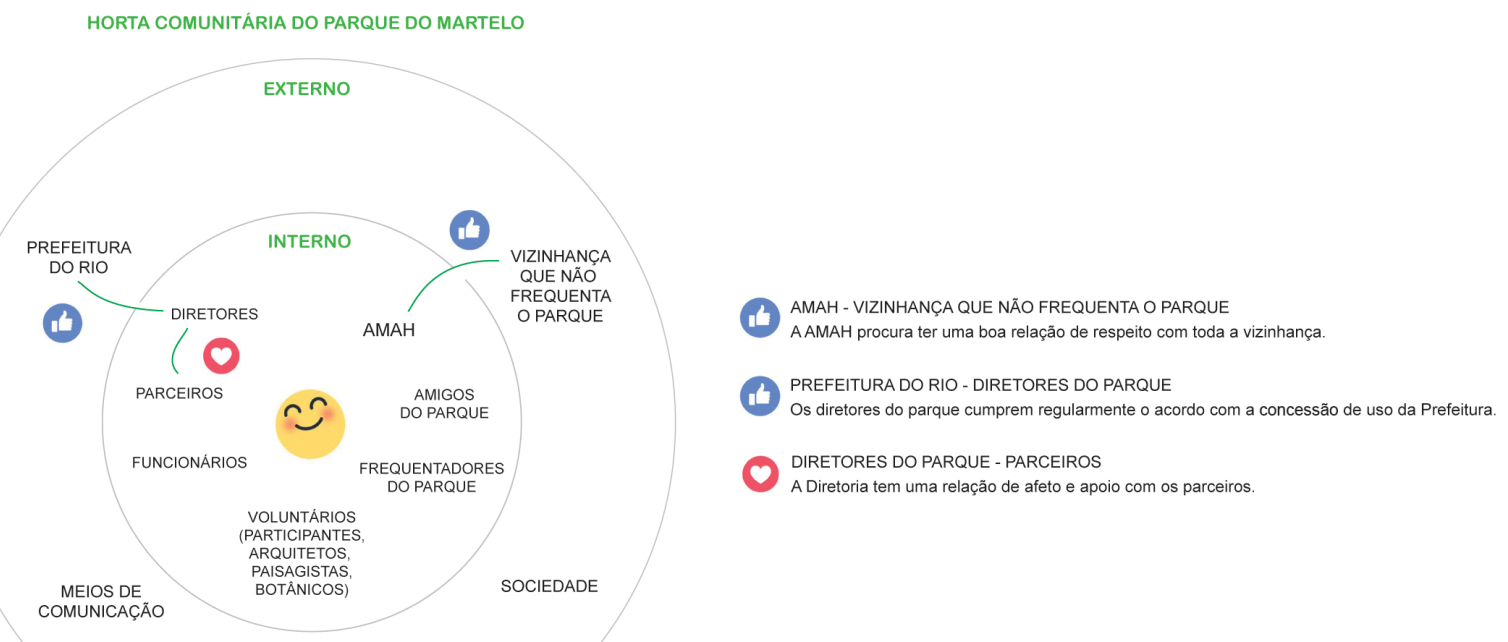

Fonte: o autor (2018).

\section{Discussão}

\subsection{Os encontros de caráter interpessoal e seu valor na transição para a sustentabilidade no contexto urbano}

Percebeu-se na entrevista que a horta baseia sua existência na produção e renovação de encontros de caráter relacional (BUBER, 1987, apud MANZINI, 2017; CIPOLLA e MANZINI, 2009). Este tipo de encontro e discussão de como podem ser projetados são temas de destaque na comunidade acadêmica que se ocupa de design para a inovação social. A grande questão envolvida é a impossibilidade de projeto direto desses encontros e a hipótese de que a prática de design atuaria como facilitadora desses processos (CIPOLLA, 2004).

Meroni (apud MANZINI, 2008, p. 64) diz que uma comunidade criativa é feita de "pessoas que inventam novos modos de vida de forma colaborativa", definição esta que cabe ao grupo de pessoas do Parque do Martelo. Muito se reflete também dentro da horta comunitária, um verdadeiro resgate a um movimento mais lento, de encontro com a vizinhança e impresso dentro dos valores do movimento Slow Food.

Manzini (2017, p. 209) reforça que "a construção dos lugares não é importante apenas para o bem-estar de indivíduos e comunidades de moradores" e também define a produção de um sistema mais resiliente como "um sistema capaz de se adaptar a acontecimentos inesperados e de sobreviver ao tempo" (MANZINI, 2017, p. 209).

\subsection{Compartilhamento de valores}

O resultado das entrevistas contextuais mostra que existe um sistema claro de atividades e processos a ser definido e projetado para a realização e gestão de uma horta comunitária. Nisto, além das relações interpessoais, o elemento motivacional foi relevante. Apenas para a horta 
existir foi necessário que muitas pessoas se engajassem primeiramente na retirada de entulhos do local para que se pudesse começar a criação dos canteiros. Esse aspecto demonstra a força de um trabalho em equipe muito grande e também a disposição de pessoas para uma ação voluntária.

O Mapa Mental evidenciou o conjunto de valores compartilhados que atuaram como elementos de caráter motivacional para o grupo, como a busca de novos princípios de interação urbana a partir do "contato com a vizinhança", até atividades de aprendizado colaborativo expresso com o termo "ensino informal". O ensino informal é uma prática produzida na horta comunitária de grande potencial, em que saberes específicos e saberes populares podem ser aprendidos na rua. A questão do voluntariado também emergiu no mapa mental: a ideia de colocar saberes profissionais a serviço de seu próprio contexto local e de vida cotidiana foi acentuada. O ATOR 2, paisagista de profissão, pode realizar um projeto paisagístico para o local ao mesmo tempo em que está à frente dos mutirões e que conta com a iniciativa de voluntários na construção e manutenção dos canteiros. As entrevistas demonstram um aspecto positivo de desenvolvimento de seus papéis dentro da horta.

\subsection{Rede de atores}

O Mapa de Stakeholders revela como a Horta do Parque do Martelo deve sua existência à constituição de uma série de relações harmoniosas com os atores internos e externos. Tal articulação institucional e interpessoal torna-se um dos grandes desafios para a constituição de iniciativas no contexto urbano. Tudo é gerenciado pelo cumprimento dos acordos (por exemplo, de concessão de uso com a prefeitura), no entanto com afeição e carinho pelos parceiros. Os diretores do Parque têm papel crucial em manter fluidas as interações entre os atores. Segundo Manzini (2017), práticas de inovação social para a sustentabilidade contam com uma articulação mutuamente benéfica entre atores no território.

\section{Considerações finais}

Este estudo teve como foco analisar as hortas comunitárias como comunidades criativas em uma abordagem do Design para Inovação Social e Sustentabilidade, com o objetivo de compreender como as relações construídas na horta comunitária do Parque do Martelo se sustentam. Os resultados do trabalho de campo foram articulados com teorias desta área do design e foram discutidos os aspectos-chave do projeto da Horta do Parque do Martelo no tocante aos padrões de relações interpessoais e institucionais que o sustentam. A utilização do Mapa Mental e do Mapa de Stakeholders foram instrumentos úteis de análise, evidenciando o sistema de valores e a relação entre os atores envolvidos na Horta. Confirmou-se que as relações interpessoais constituem o aspecto central neste tipo de prática urbana e que seus processos de facilitação devem estar no centro de uma prática de design que se ocupa deste tipo de iniciativa.

É possível perceber que existe um grande empenho de trabalho e luta para a manutenção do Parque do Martelo frente à grande especulação imobiliária que vem sendo praticada na cidade. Por essa razão, a construção da horta comunitária demonstra uma democratização social do território na cidade e ainda aponta para a geração de cenários futuros onde as hortas poderão ser um potente local de encontro na cidade assim como a praia, as praças e as esquinas.

A partir da perspectiva das comunidades criativas e do bem-estar, observa-se no Parque do Martelo um universo que gera frutos reais e simbólicos.

A criação de hortas comunitárias nas cidades representa o que Manzini (2008, p. 25) 
chama de descontinuidade sistêmica: "uma forma de mudança em cujo final o sistema em questão - em nosso caso, o complexo sistema sociotécnico no qual as sociedades industriais estão baseadas - será diferente, estruturalmente diferente, daquilo que tivemos até hoje." As hortas comunitárias simbolizam uma ressignificação do espaço, passando a ser uma área de preservação verde e um espaço de convívio. Conclui-se que a ideia de bem-estar em comunidade é constantemente construída no parque, pois muitas das relações entre pessoas de classe média estão longe do convívio e do compartilhamento de bens. Manzini (2008) coloca a ideia do bemestar dentro de um "processo de aprendizagem social", onde a sociedade se molda e se reajusta de acordo com a qualidade de vida. A cooperação vivida no espaço da horta comunitária gera valores humanos que resgatam a prática de realização conjunta proposta por Sennett (2012).

Vale destacar que os valores interpessoais gerados dentro da comunidade são de abundância em relação ao convívio com a natureza e com a comunidade. Em meio a horta, existe na verdade uma grande produção de afetos, uma vez que pouco se conta com a produção e colheita dos alimentos. Dentro dos valores é perceptível a sustentabilidade mútua dos homens com a comunidade, tal como Buber $(1987$, p. 83) descreve: "o homem nasce na comunidade" e "ela é sua condição, ele vive, respira nela, ela o sustenta".

A investigação relatada deixa claro aspectos fundamentais a serem considerados na prática de design que se ocupa. Faz-se necessário também aprofundar o estudo e compreender as reais motivações para a criação de hortas comunitárias e como se dá a construção de laços afetivos dentro da comunidade, assim como as novas relações com o alimento dentro da cidade. A horta do Parque do Martelo faz parte de um cenário possível de vivência em comunidade, e de que como esta horta poderia ser reproduzida em outros bairros por meio de uma proposta do design de protótipos para o favorecimento da criação dos ambientes das hortas comunitárias. Por meio de estratégias de design sistêmico será possível criar uma gestão para as hortas comunitárias que, futuramente, possam fazer parte de um programa do Estado do Rio de Janeiro.

\section{Referências}

BUBER, M. Sobre comunidade. São Paulo: Perspectiva, 1987.

CIPOLLA, C. Tourist or Guest - Designing Tourism Experiences or Hospitality Relations? In: WILLIS, A.-M. (Ed.). Design Philosophy Papers: Collection Two. Ravensbourne- Australia: Team D/E/S Publications, 2004.

CIPOLLA, C.; MANZINI, E. Relational services. Knowledge Technology \& Policy, [S.I.], v. 22, p. 4550, Springer, 2009.

MANZINI, E. Design para a inovação social e sustentabilidade. Cadernos do Grupo de Altos Estudos, Programa de Engenharia de Produção da Coppe/UFRJ, Rio de Janeiro, v. I, 2008.

MANZINI, E. Design: quando todos fazem design: uma introdução ao design para inovação social. São Leopoldo, RS. Ed. UNISINOS, 2017.

MAPAS MENTAIS. Disponível em: <http://estudoesquematizado.com.br/mapas-mentais/>. Acesso em: 25 mar. 2018.

PAPANEK, V. Design for the real world: human ecology and social change. 2. ed. Chicago: Chicago Review Press, 2005.

PENIN, L. (Ed.). Amplifying Creative Communities New York City. NYC: Parsons DESIS LAB, 2012. 
SENNETT, R. Juntos: Os rituais, os prazeres e a política da cooperação. Rio de Janeiro: Record, 2012. $377 \mathrm{p}$.

STICKDORN, M.; SCHNEIDER, J. (Org.). Isto é design thinking de serviços: fundamentos, ferramentas, casos. Porto Alegre: Bookman, 2014.

THACKARA. J. Plano B: o design e as alternativas viáveis em um mundo complexo. Tradução de Cristina Yamagami. São Paulo: Saraiva: Versar, 2008. 